\title{
The effects of outward-pointing arrowheads on the Mueller-Lyer illusion in pigeons
}

\author{
RICHARD W. MALOTT, MARILYN KAY MALOTT AND JOHN POKRZYWINSKI \\ WESTERN MICHIGAN UNIVERSITY
}

In an earlier analysis of the Mueller-Lyer illusion in pigeons it was found that when birds trained with flat-vertical arrowheads were tested with outward pointing arrowheads, the rate of responding increased monotonically as a function of line length. It was hypothesized that the gradients did not have a peak because the effect of the illusion was great enough to cause the peak to shift outside the range of test stimuli used. The data of the present experiment show this hypothesis to be correct. A shorter training stimulus was used; this effectively increased the upper limit of the test range, and the peaked gradients were obtained.

An illusion is defined as the condition in which the point of subjective equality (PSE) does not equal the point of objective equality (POE). Thus, in studying illusions in animals one could say that an illusion has occurred if the peak of a generalization gradient (PSE) does not equal the value of the training stimulus (Malott, 1967).

In an analysis of the Mueller-Lyer illusion using pigeons, the Ss were trained to peck a key when a 1.3 $\mathrm{cm}$ horizontal line with flat-vertical arrowheads on each end of it was projected on the response key (Malott \& Malott, 1967). The birds were not reinforced for responding when the key was dark. During generalization testing, half of the birds were tested with $90^{\circ}$ arrowheads (inward-pointing) and the other half with $270^{\circ}$ arrowheads (outward-pointing) on each end of the line. Curves from tests with inward-pointing arrowheads were more or less like the curves with flat-vertical arrowheads. Peaks were at the training value. If there were any differences at all, the gradients with the inward-pointing arrowheads were more variable and broader. The tests with the outward-pointing arrowheads showed an increase in response rate as the length of the test line was increased. However, the gradients did not peak. It was hypothesized that the effect of the illusion was great enough to cause the peaks to shift outside the range of test stimuli used. The present experiment was designed to test this hypothesis by using a shorter training stimulus and, thus, increasing the upper range of the test stimuli.

Method

The Ss were six experimentally naive white Carneaux barren hen pigeons. They were maintained at $70 \%$ of their free-feeding body weight.

The response key was transilluminated by a projector. An example of the training stimulus (S+) is shown on the left side of Fig. 1. The horizontal line was $0.7 \mathrm{~cm}$ and the flat-vertical arrowheads on each end were $0.7 \mathrm{~cm}$.
After initial shaping in the presence of the $S+$, the birds were reinforced for every response when the $S+$ was on the key. No responses were relnforced when the key was dark (S-). The stimulus was terminated after every reinforcement and stayed off for $30 \mathrm{sec}$ of no responding. That is, a response during the $30 \mathrm{sec} \mathrm{S}-$ period caused the $30 \mathrm{sec}$ interval to recycle. Thus, the S+ was only presented after 30 sec had elapsed without a response while the key was dark.

The reinforcement requirements in the presence of the S+ were gradually increased until the pigeons were responding on a random-interval schedule of $64 \mathrm{sec}$ (RI64-sec) (cf., Farmer, 1963).

After 15 days of training on the RI64-sec schedule, each pigeon was given a generalization test over various lengths of line which had outward-pointing arrowheads $\left(270^{\circ}\right)$ on each end. This type of stimulus is shown on the right side of Fig. 1. The length of each side of each arrowhead was $.35 \mathrm{~cm}$. The pigeons then received a second test after another week of training. During this test, the lines had flat-vertical arrowheads like the training stimulus. The birds were retested with the outward-pointing arrowheads after an additional two weeks of training. Then the test with the flat-vertical arrowheads was repeated after three more weeks of training for Birds B-2-7, B-2-8 and B-2-9. The range of the line length in the tests with the flat-vertical arrowheads for Birds B-2-7, B-2-8 and B-2-9 was 0.3 to $1.7 \mathrm{~cm}$. (This included eight stimuli separated by $0.2 \mathrm{~cm}$.) This was done to see both sides of the gradient. In all of the other tests the range was from 0.7 to $2.3 \mathrm{~cm}$. This included eight stimuli separated by $0.2 \mathrm{~cm}$ except in that the $0.9 \mathrm{~cm}$ stimulus was omitted. This was to give the upper range enough width to contain the peak shift of the gradients with outward-pointing arrowheads. For an example of the two types of stimuli see Fig. 1. Resulfs and Discussion

Only five birds gave enough responses during any of the generalization tests with the flat-vertical arrow-
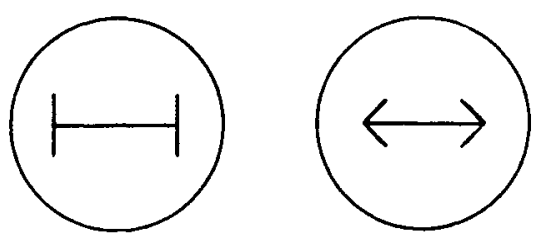

Fig. 1. Examples of the two types of stimuli used in the generalization tests. The stimulus on the left was also used in training. 


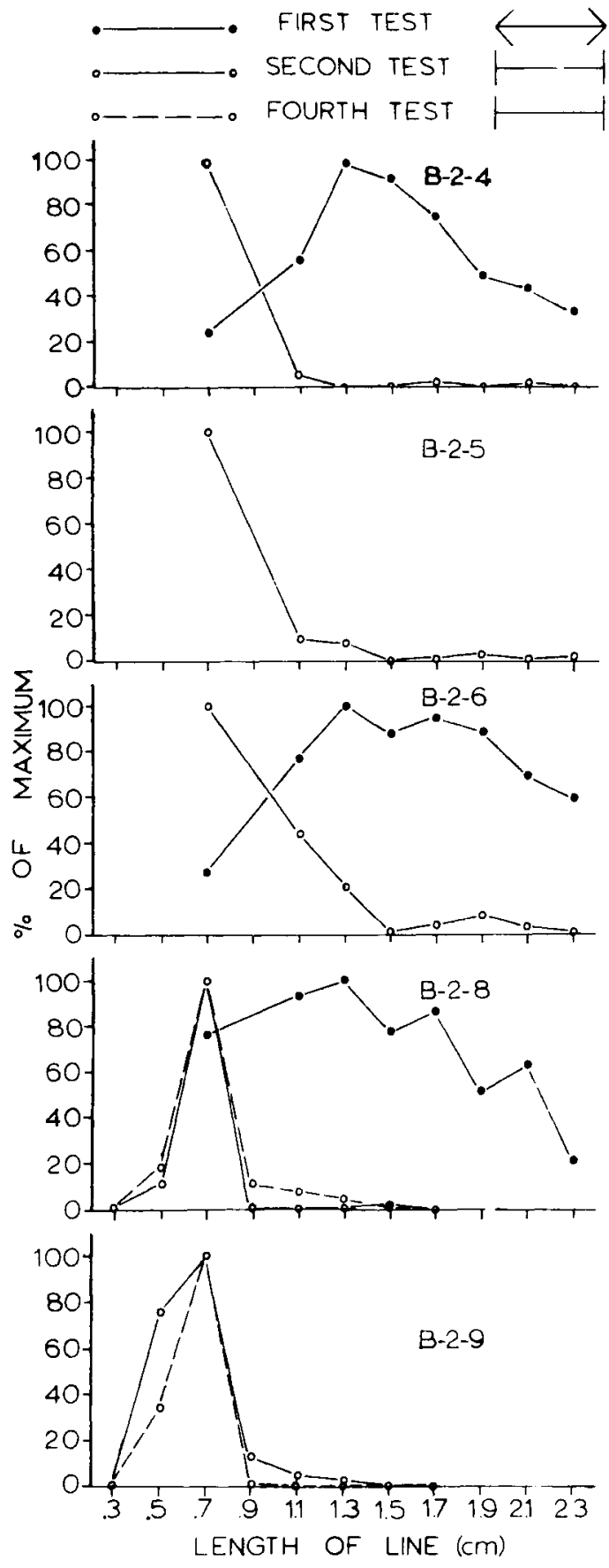

Fig. 2. The percent of the maximum amount of responses (the peak) as a function of line length. Data were obtained from the birds which met the criterion for reliable gradients. The criterion was a minimum of 50 responses at the peak. The absolute number of responses occurring at the peak for Birds B-2-4 through B-2-9 are as follows: Test 1: 68, 12, $182,0,52$, and 23 ; Test $2: 130,181,381,37,53$, and 365 ; Test $3: 0,0$, 0, 0, 0, and 0; and Test 4 (Birds B-2-7 through B-2-9 only): 29, 247, and 473. heads to yield reliable gradients, and only three met the same criterion for the tests with the outwardpointing arrowheads. Bird B-2-7 never responded enough in any of the test situations to yield reliable gradients. It is possible that the birds soon formed an implicit discrimination between training and testing sessions. That is, when a line appeared with outwardpointing arrowheads, no responses would be reinforced since it was a testing and not a training session. This assumption is supported by the fact that no reliable gradients could be obtained for any of the pigeons during the third test (inward-pointing arrowheads) and that none of them even responded during the first block of test trials. Criterion for using generalization data was that at least 50 responses occur at the point of maximum responding.

All the gradients obtained with the flat-vertical arrowheads peaked at $0.7 \mathrm{~cm}$, the training length. The gradients were very steep with very little responding to any other stimulus value. This indicated that the birds were discriminating on the basis of line length and generalized very little to other lengths of line with the same type of arrowheads. The curves which ranged from 0.7 to $2.3 \mathrm{~cm}$ look flatter than the ones which ranged from 0.3 to $1.7 \mathrm{~cm}$ because 0.9 was skipped in the former curves. The curves which ranged from 0.3 to 1.7 are symmetrical around $0.7 \mathrm{~cm}$.

The gradients obtained with the outward-pointing arrowheads, however, were somewhat flatter and symmetrical around $1.3 \mathrm{~cm}$. This not only indicates the operation of the Mueller-Lyer illusion in terms of a peak shift, but also shows that the illusion causes a high degree of generalization.

By responding maximally to the lines with the outward-pointing arrowheads at $1.3 \mathrm{~cm}$ (PSE), the pigeons were indicating that with these arrowheads this length of line "appeared" to be equal to the length of the training stimulus $(0.7 \mathrm{~cm})$. The gradients which were obtained with the flat-vertical arrowheads were used as control data. They peaked at $0.7 \mathrm{~cm}$ (POE), thus, ruling out the possibility that the peak shift occurred as a function of the conditioning procedure (cf., Hanson, 1959).

\section{References}

FARMER, J. Properties of behavior under random interval reinforcement schedules. J. exp. Anal. Behav., 1963, 6, 607-616.

HANSON, H. M. Effects of discrimination training on stimulus generalization. J. exp. Psychol., 1959, 58, 321-333.

MALOTT, R. W. Perception revisited. Paper read at the meeting of APA in New York City, 1966.

MALOTT, R. W., \& MALOTT, MARILYN K. An analysis of the MuellerLyer illusion in terms of stimulus generalization. J. exp. Anal. Behav., 1967, submitted for publication.

Note

1. This research was supported by Public Health Service Grant MH 13178-01. 